\title{
Pamukta İlişkilendirme Haritalaması Yöntemiyle Gossypol ile İlişkili Markörlerin Belirlenmesi
}

\author{
Adem BARDAK ${ }^{1} \quad$ M. Said FIDAN ${ }^{2} \quad$ Elif DAĞĞEÇEN $^{3} \quad$ Halil TEKEREK $^{3}$ \\ Sadettin ÇELIK ${ }^{3} \quad$ Döne PARLAK ${ }^{3} \quad$ Khezir HAYAT ${ }^{4}$
}

\begin{abstract}
${ }^{1}$ Kahramanmaraş Sütçü İmam Üniversitesi, Ziraat Fakültesi, Tarımsal Biyoteknoloji Bölümü, Kahramanmaraş,
${ }^{2}$ Bursa Teknik Üniversitesi, Orman Fakültesi, Orman Endüstri Mühendisliği Bölümü, Bursa

${ }^{3}$ Kahramanmaraş Sütçü İmam Üniversitesi, Fen Bilimleri Enstitüsü, Tarımsal Biyoteknoloji ABD, Kahramanmaraş

${ }^{4}$ Kahramanmaraş Sütçü İmam Üniversitesi, Fen Bilimleri Enstitüsü, Biyomühendislik ve Bilimleri ABD,

Kahramanmaraş

$\bowtie$ : adembardak@ksu.edu.tr
\end{abstract}

Geliş (Received): 03.11.2017

Kabul (Accepted): 15.12.2017

\begin{abstract}
ÖZET: Pamuk dünyada ve ülkemizde önemli bir tekstil hammaddesi olmakla birlikte aynı zamanda lifi alındıktan sonra yağ ve yem sanayisi ile birlikte birçok endüstri koluna hammadde sağlamaktadır. Pamuk tohumunun yem ve yağ kaynağı olarak insan ve hayvan beslenmesinde kullanımı tohumun içerdiği gossypol maddesinden dolayı sınırlı kalmaktadır. Pamuk sslah hedeflerinden biri de tohumunda gossypol içermeyen çeşitlerin geliştirilmesidir. Böylece pamuktan elde edilen yağın kalitesi ve insan beslenmesinde kullanım yaygınlığı artabilecektir. Bu çalışma ile markör destekli seleksiyonu (MAS: Marker Asisted Selection) mümkün kılabilecek olan gossypol ile ilişkili markör geliştirilmesi amaçlanmıştır. Çalışma pamuk genetik stokumuzda bulunan ve yapılacak islah programlarında ebeveyn olarak kullanılabilecek 48 adet pamuk genotipi ile yürütülmüştür. İlişkilendirme haritalaması çalışmalarında fenotipik veri olarak gövde $(\operatorname{adet} / \mathrm{cm} 2)$, yaprak $(\operatorname{adet} / \mathrm{cm} 2)$, koza $(\operatorname{adet} / \mathrm{cm} 2)$ ve tohumdaki (adet/mm2) gossypol beze sayıları ve tohum HPLC analizi verileri kullanılmıştır. Genotipik veri olarak genotipler arasında 37 adet SSR markörünün taranması sonucu elde edilen, 83 adet polimorfik bant kullanılmıştır. Genel Linear Modelde (GLM); gövdedeki gossypol ile ilişkili 1 adet, kozadaki gossypol ile ilişki 4 adet, yapraktaki gossypol ile iliş̧kili 3 adet, tohumdaki gossypol ile ilişkili 8 adet, tohum HPLC sonuçları ile ilişkili 4 adet markör belirlenmiştir. Karışık linear modelde (MLM) ise gövdedeki gossypol ile ilişkili 1 adet, kozadaki gossypol ile ilişki 12 adet, yapraktaki gossypol ile ilişkili 3 adet, tohumdaki gossypol ile ilişkili 3 adet markör belirlenmiştir. Her iki yöntemde de belirlenen 5 adet (BNL3130, BNL3627, JESPR7, BNL3449, BNL387, JESPER178) markör gossypol yönünden oluşturulmuş F2 popülasyonları gibi özel popülasyonlarda doğrulaması yapılarak, markör destekli seleksiyonda kullanımları mümkün olacaktır.

Anahtar Sözcükler: Pamuk, Gossypol, İlişkilendirme haritalaması, Genetik stok, SSR
\end{abstract}

\section{Association Mapping for Gossypol Contents in Cotton}

\begin{abstract}
Cotton is an important raw material for textile all over the globe and in our country; after fiber it also supplies raw materials to oil and feed industry. Cottonseed used as a fat in humans and as feed in animals is limited due to gossypol. The goal of cotton breeders is to develope cultivars without gossypol. Therefore, cottonseed oil quality matters a lot for increasing use in human diet. In this study it was aimed at to develope markers related to gossypol which will be useful for marker assisted selection (MAS). The study was carried out with 48 cotton genotypes that can be used as a resource in the breeding programs. Phenotypic data were used for association mapping studies. Gossypol number was counted in stem, leaf and boll at $\mathrm{cm} 2$ while gossypol contents in seeds were measured by using HPLC. 37 SSRs were screened among the genotypes for getting of genotypic data and found 83 polymorphic allels. Marker trait associations were observed using General Linear Model; 1, 4, 3, 8, 4 gossypol associations with stem, boll, leaf, seed and HPLC seed were determined. While Mixed Linear Model (MLM) resulted 1, 12, 3, 3 associations with stem, boll, leaf and seed respectively. As a whole five common SSR markers BNL3130, BNL3627, JESPR7, BNL3449, BNL387, JESPER178 were associated with gossypol, these will be verified in F2 population and ultimately used for marker assisted selection.

Keywords: Cotton, Gossypol, Association mapping, Germplasm, SSR
\end{abstract}

\section{GİRis}

Pamuk lifinin yanında tohumundan elde edilen yağ 1 insan beslenmesinde kullanılırken, yağı alındıktan sonra geriye kalan küspesi hayvan beslenmesinde önemli bir protein kaynağıdır (Cherry ve ark 1978; Cherry 1983; Cherry ve Leffler 1984). Bir yağ bitkisi olarak pamuk dünyada soya, kolza ve ayçiçeğinden sonra dördüncü sırada yer alırken (Anonim 2017) bitki protein kaynağ olarak soyadan sonra ikinci sırada yer almaktadır
(Benbouza ve ark., 2010). Yağ oranı tür, çeşit ve lokasyonlara göre (kabuklu olarak) havlı tohumlarda $\% 17-24$, havsiz tohumlarda \%20-30; iç olarak ise \%2342 arasında değişmektedir (Sezer, 1981; Bölek ve ark., 2016). Tohum protein içeriği ise kabuklu olarak tür, çeşit ve çevre koşullarına göre \%20-40 (Buser ve Abbas, 2001), iç olarak \%34-46 (Bölek ve ark., 2016) arasında değiştiği bildirilmektedir. Ayrıca doymamış yağ asitleri ve "E" vitamini yönünden de oldukça zengin 
olup bu vitamin anti-kanserojen özelliği yanında damar hastalıkları, katarakt, parkinson ve alzheimer hastalıklarını önleyici olarak kullanılmaktadır (Vroh Bi ve ark., 1998; Bölek ve ark., 2016).

Pamuk tohumunun tüm bu özelliklerine karşın insan ve hayvan beslenmesi yönünden bazı dezavantajları bulunmaktadır. Özellikle, gossypol içeriği yüksek tohumların gıda hammaddesi olarak kullanımı sınırlı olmaktadır (Emiroğlu, 1974). Pamuk tohumunda bulunan gossypol, temelde terponeid aldehit olup tek mideli hayvanlar ve insanlar için zararlı ve toksiktir (Lusas ve Jividin 1987). Buna karşın gossypol ve ilgili terponeid aldehitler çeşitli zararlılar ile fungal ve bakteriyal hastalıklara karşı doğal toleranlık/dayanıklılık kazandırır (Stipanovic ve ark., 1994; Altman ve ark., 1987; Percy, 1996). Gossypol bezeleri içermeyen mutant pamuk genotipi Mc Michael (1954) tarafindan keşfedilerek gossypolsüz tohuma sahip ticari çeşit geliştirmek için ebeveyn olarak kullanılmıştır. $\mathrm{Bu}$ çalışmalar neticesinde gossypolsüz çeşitlerin böceklere hassas hale gelmesinden dolayı çabalar ticari başarısızlık olarak sonuçlanmıştır (Altman ve ark., 1987). İdeal bir pamuk çeşidi insan ve hayvan beslemesi açisından tohumunda gossypol bulundurmamalı, hastalık ve zararlılara karşı dayanıklılık için ise vejatatif aksamında gossypol bulundurmalıdır (Benbouza ve ark., 2010).

Bitkinin değișik parçalarında ya da organlarında beze oluşumunun $g l l, g l 2, g l 3, g l 4, g l 5$ ve $g l 6$ genleri tarafindan yönlendirildiği (Pauly, 1979), ticari pamuk çeşitlerinde gossypol içeren bezelerin oluşumunun birbirlerinin homoloğu olan $G l 2$ ve $G l 3$ dominant genler tarafindan kontrol edildiği bildirilmektedir (Vroh Bi ve ark., 1999). Resesif gll ve gl6 allellerinin gossypolsüz koza oluşumunda; $g l 2, g l 3, g l 4$ ve $g l 5$ allelerinin ise, gossypolsüz bitki oluşumunda etkili olduğu bildirilmektedir (Kohel, 1973). Gl2 allelinin A genomunun 12. kromozomunda ve $G l 3$ allelinin ise, D genomunun 26. kromozomda yer aldığ 1 belirtilmektedir Çizelge 1. Çalışmada kullanılan genotipler

\begin{tabular}{|c|c|c|c|c|c|c|c|c|}
\hline KOD & Cesit & Tür & KOD & Cesit & Tür & KOD & Cesit & Tür \\
\hline 1 & 2421-A & G.hirsutum L. & 17 & DPL-20 & G.hirsutum L. & 33 & TAMCOT CABCS & G.hirsutum L. \\
\hline 2 & 308 (CAMPO) & G.hirsutum L. & 18 & ERŞAN-92 & G.hirsutum L. & 34 & LIFSİZ & G.hirsutum L. \\
\hline 3 & $8106-2$ & G.barbadense L. & 19 & FIBBERMAX 832 & G.hirsutum L. & 35 & AŞKABAT 100 & G.barbadense L. \\
\hline 4 & 919 (LİDER) & G.hirsutum L. & 20 & FIBERMAX 958 & G.hirsutum L. & 36 & EGE 69 & G.hirsutum L. \\
\hline 5 & ACALA MAXA & G.hirsutum L. & 21 & G.B.58 & G.barbadense L. & 37 & GOSSİPOLSÜZ 86 & G.hirsutum L. \\
\hline 6 & ACALA-552 & G.hirsutum L. & 22 & GARANT & G.hirsutum L. & 38 & KURAK-1 & G.hirsutum L. \\
\hline 7 & ALEPPO 40 & G.hirsutum L. & 23 & GiZA 70 & G.barbadense L. & 39 & YEŞİL LİF & G.hirsutum L. \\
\hline 8 & AŞKABAT-91 & G.barbadense L. & 24 & GïA-45 & G.barbadense L. & 40 & ACALA ROYALE & G.hirsutum L. \\
\hline 9 & AYDIN-110 & G.hirsutum L. & 25 & GİZA-75 & G.barbadense L. & 41 & ACALA PREMA & G.hirsutum L. \\
\hline 10 & AZERBAYCAN 3038 & G.hirsutum L. & 26 & KASHINAT & G.hirsutum L. & 42 & SPNXHQBPIS-1-94 & G.hirsutum L. \\
\hline 11 & BAHAR 82 & G.barbadense L. & 27 & LACHATA & G.hirsutum L. & 43 & YB162 & G.hirsutum L. \\
\hline 12 & BAHAR-14 & G.barbadense L. & 28 & $\begin{array}{l}\text { MARCEL LEAF } \\
(\text { BROWN) }\end{array}$ & G.hirsutum L. & 44 & YB193 & G.hirsutum L. \\
\hline 13 & BELİ İVOR-432 & G.hirsutum L. & 29 & PAYMASTER 2379 & G.hirsutum L. & 45 & YB194 & G.hirsutum L. \\
\hline 14 & CARMEN & G.hirsutum L. & 30 & STN 8A & G.hirsutum L. & 46 & YB195 & G.hirsutum L. \\
\hline 15 & DELTAOPAL & G.hirsutum L. & 31 & SUREGROW 125 & G.hirsutum L. & 47 & YB196 & G.hirsutum L. \\
\hline 16 & DP-388 & G.hirsutum L. & 32 & ŞAHİN 2000 & G.hirsutum L. & 48 & W35 & G.barbadense L. \\
\hline
\end{tabular}

Araziden toplanan bitki örneklerinde; Gövde, koza, yaprak gosypol sayıları (adet $\mathrm{cm}^{-1}$ ) ve tohumdaki gosypol sayısı (adet $\mathrm{mm}^{-1}$ ) mikroskop altında 2 yıl süreyle sayılmıştır. HPLC analizleri yöntemine göre tek
(Endrizzi, 1962; Samora ve ark., 1994). Gossypium cinsi içerisinde tohumu gossypolsüz ancak bitki yapısı gossypollü genotiplere sadece Avustralya kökenli yabani türlerden $G$. sturtia ile $G$. hibiscoidea (C ve $G$ genomları) türlerinde rastlanmaktadır (Altman ve ark., 1987; Rooney ve ark., 1991).

Pamuk tekstil endüstrisine olduğu kadar yağ ve yem sanayisine de önemli derecede hammadde sağlamaktadır. Verim ve lif kalitesinin arttırılmasının yanında yă̆ ve yem kalitesinin de arttırılması gerekmektedir. Yağ ve yem kalitesinin arttırılmasının yolu tohumunda gossypol bulundurmayan, bitki aksamı gossypollü çeşitlerin geliştirilmesinden geçmektedir. Böyle bir çeşidin 1slahı geleneksel bitki ıslahı ile oldukça zor olup moleküler yöntemlerle desteklenmesi gerekmektedir.

Moleküler yöntemlerle istenilen özelliklere bağl1 markörler tespit edilerek, erken açılım gösteren islah generasyonlarında markörlere dayalı seleksiyon (marker asisted selection) (MAS) mümkün olabilmektedir. Markörlere dayalı seleksiyon (MAS) yapabilmek için ilgilenilen özelliklerle ilişkili QTL'lerin (kantitatif özellik lokusu) geliştirilmesi gerekmektedir. QTL belirlemede yaygın olarak linkage haritalama (Linkage Mapping) ve ilişkilendirme haritalaması (Association Mapping) yöntemleri kullanılmaktadır (Bardak, 2016). Linkage haritalamada aynı ana ve babadan gelen spesifik popülasyonlara $\left(\mathrm{F}_{2}, \mathrm{BC}_{1}, \mathrm{BC}_{2}\right.$, RIL) ihtiyaç duyulurken, ilişkilendirme haritalaması direkt genetik stok materyallerinde uygulanabilmektedir (Zhu ve ark., 2008).

$\mathrm{Bu}$ çalışma ile markör destekli seleksiyonu (MAS: Marker Asisted Selection) mümkün kılabilecek olan gossypol ile ilişkili markör geliştirilmesi amaçlanmıştır.

\section{MATERYAL ve METOT}

Çalışmada 10 adet $G$. barbadense L. türüne ait, 38 adet $G$. hirsutum L. türüne ait, toplam 48 adet pamuk genotipi kullanılmıştır (Çizelge 1). y1l analiz edilmiştir.

Her bir genotipi temsil eden yaprak örnekleri kuru buz içerisinde laboratuara getirilmiş ve Zhang ve Stewart (2000)'e göre DNA izolasyonu yapılmıştır. Çalışmada 
genotipleme 37 SSR DNA markörü kullanılarak Bardak ve Bölek (2012) tarafindan belirtilen yönteme göre yapılmıştır.

Kümeleme analizi Q-matriks verileri STRUCTURE paket programında analiz edilmiştir. Genotipik ve fenotipik veriler kullanılarak TASSEL 5.0 (Pritchard ve ark., 2000) paket programında ilişkilendirme haritalaması (association mapping) analizleri yapılmıştır.

\section{BULGULAR ve TARTIŞMA}

\section{Genotiplerin genetik yapı analizi}

Bayesian yöntemini model alan STRUCTURE 2.3.4 yazılımı kullanılarak, dominant genotipik verilerle kümeleme analizi yapılmıştır (Pritchard ve ark. 2000). Kümeleme sayısını belirlemek amacıyla $\mathrm{K}$ değeri hesaplanmıştır. Program ayarları K değeri 2 ile 10 arasında çalıştırılmış ve permütasyon modülünde 100010.000 seçilip her bir $\mathrm{K}$ değeri için 5 tekrar yapılarak ideal $\mathrm{K}$ değeri hesaplanmış ve 3 olarak bulunmuştur

Şekil 2'ye bakıldığında genotiplerin genetik olarak 3 gruba ayrıştığ görülmektedir. Her bir rengin farklı bir genetik yapıyı temsil ettiği söylenebilir. Şekil 2 incelendiğinde genetik köken olarak birbirine yakın

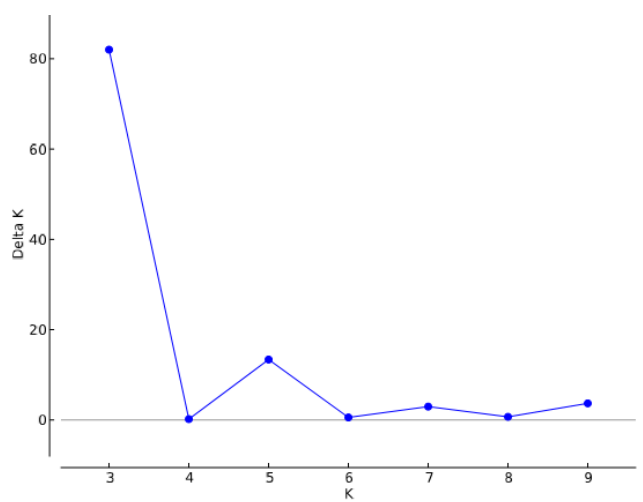

Şekil 1. Genetik yapı analizi için ideal $\mathrm{K}$ değeri (Şekil 1). hesaplama grafiği

genotiplerin genetik olarak yakın oldukları görülmektedir. Genetik olarak birçok genotipin birbirinden etkilendiği görülmektedir.

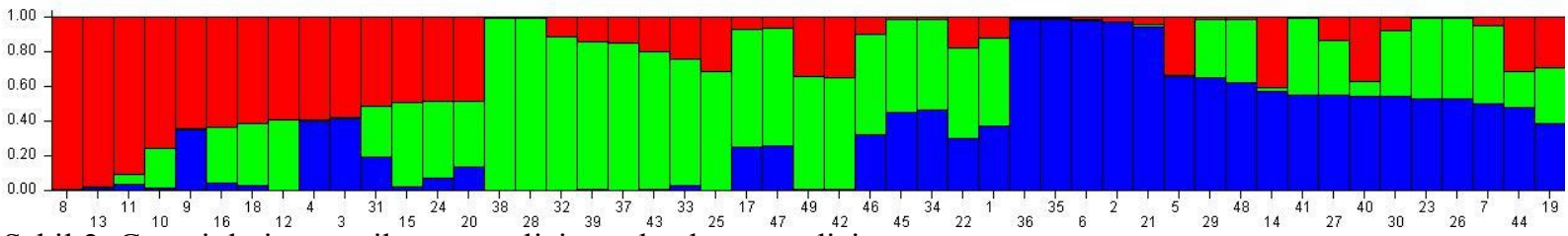

Şekil 2. Genotiplerin genetik yapı analizi gruplandırma analizi

\section{Bağlantı denksizliğinin (LD: Linkage \\ Disequilibrium) belirlenmesi}

37 adet SSR markör çiftinin oluşturduğu polimorfik lokuslar arasındaki ilişkilerin belirlenmesi bağlantı deksizliği (LD) yöntemine göre yapılmıştır (Şekil 3). Bağlantı denksizliği analizinde 4560 karşılaştırma sonucunda, analiz edilen SSR'larm \% 11'i $\mathrm{r}^{2} \geq 0.1$ bulunurken, $r^{2} \geq 0.1$ ve $p \leq 0.005$ önemlilik düzeyinde SSR markör çiftlerinin \% 6' S1 önemli bulunmuştur. Eğer $\mathrm{r}^{2} \geq 0.1$ olursa, genomda marker uzaklığ $1010 \mathrm{cM}$ olduğu, $r^{2} \geq 0.2$ olduğunda ise marker uzaklığının yaklaşık 1-2 cM daha azaldığı ve 6-8 cM'a düştüğü bildirilmektedir (Abdurakhmonov ve ark., 2008).

\section{Gossypol ile ilişkili markörlerin belirlenmesi}

İlişkilendirme analizleri genotipik, fenotipik ve Qmatriks verileri kullanılarak TASSEL paket programında genel linear model (GLM) ve 10000 permutasyon modülü seçilerek yapılmıştır (Çizelge 2). Yapılan ilişkilendirmede, $\mathrm{P}<0.05$ 'e göre 17 adet markör belirlenirken, $\mathrm{P}<0.01$ 'e göre iki adet markör belirlenmiştir. Gövdedeki gossypol sayısı ile bir (BNAL3103), kozadaki gossypol sayısı ile dört (BNL3103, BNL3871, BNL3627, JESPR7), yapraktaki gossypol sayısı ile üç (BNL3449, BNL3545, JESPR70), tohumdaki gossypol sayıs1 ile yedi (BNL2921, BNL3103, BNL3449, BNL387, NAU1162, NAU2173, MGHES24), tohumdaki HPLC oranı ile dört (BNL3860,
BNL3627, JESPR70，JESPR178) adet ilişkili markör belirlenmiştir.

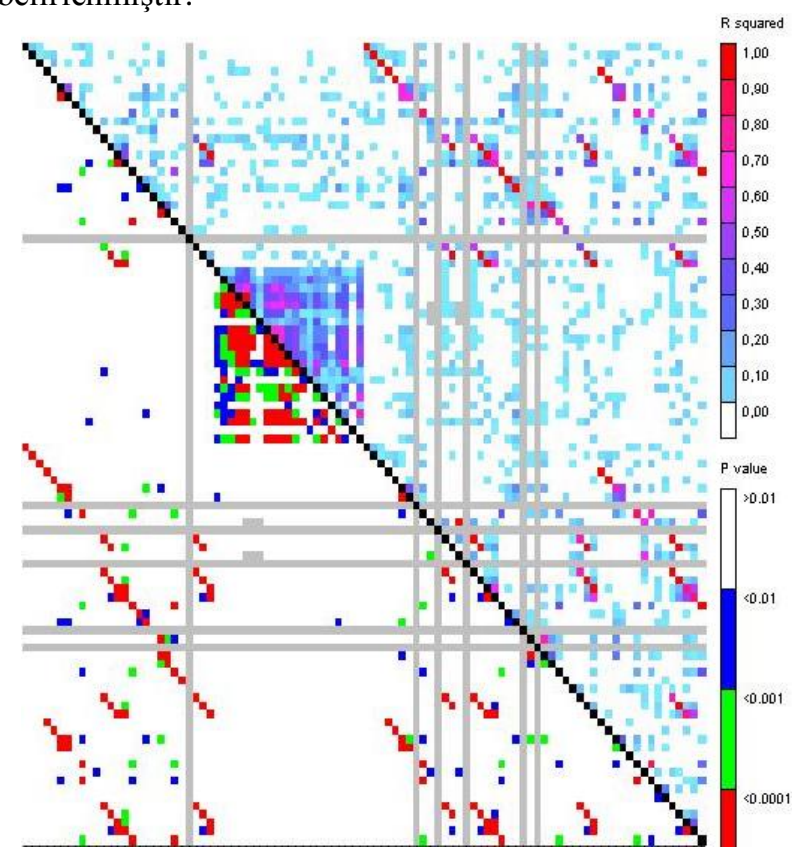

Şekil 3. Bağlantı denksizliği (LD) grafiği 
Çizelge 2. Genel linear model (GLM) de gossypol ile ilişkili markörler

\begin{tabular}{lllll}
\hline Özellik & Markör & Kromozom & $\mathrm{F}$ & $\mathrm{p}$ \\
\hline Gövde & BNL3103 & 10 & 5.807 & 0.020 \\
Koza & BNL3103 & 10 & 4.807 & 0.034 \\
Koza & BNL3871 & 7 & 5.443 & 0.025 \\
Koza & BNL3627 & 8,24 & 11.023 & 0.002 \\
Koza & JESPR7 & 16,20 & 5.213 & 0.028 \\
Yaprak & BNL3449 & 7 & 5.166 & 0.028 \\
Yaprak & BNL3545 & 2,14 & 5.669 & 0.022 \\
Yaprak & JESPR70 & 24 & 5.669 & 0.022 \\
Tohum & BNL2921 & 1 & 4.508 & 0.040 \\
Tohum & BNL3103 & 10 & 6.428 & 0.015 \\
Tohum & BNL3449 & 7 & 4.106 & 0.049 \\
Tohum & BNL387 & 4,9 & 5.223 & 0.028 \\
Tohum & NAU1162 & - & 4.888 & 0.033 \\
Tohum & NAU2173 & 14 & 4.508 & 0.040 \\
Tohum & MGHES24 & 2 & 4.508 & 0.040 \\
HPLC & BNL3860 & 2,4 & 5.523 & 0.026 \\
HPLC & BNL3627 & 8,24 & 12.402 & 0.001 \\
HPLC & JESPR70 & 24 & 4.355 & 0.046 \\
HPLC & JESPR178 & 18 & 5.523 & 0.026 \\
\hline
\end{tabular}

Karıșık linear model (MLM: mixed linear model) ilişkilendirme analizinde genotip, fenotip, Qmatriks ve kinship verileri kullanılarak TASSEL 5 programında yapılmıştır (Çizelge 3). Yapılan analiz sonucunda gövde ile bir (BNL3103), koza ile oniki (BNL2646, BNL3449, BNL387, BNL3492, BNL3535, BNL3627, BNL3895, NAU2714, NAU2761, NAU1302, JESPR178, JESPR230), yaprak ile üç (BNL3103, JESPR7, MUCS404) ve tohum ile üç (BNL3535, JESPR178, JESPR230) ilişkili markör belirlenmiştir.

Çizelge 3. Karışık linear model (MLM) de gossypol ile ilişsili markörler

\begin{tabular}{|l|l|c|l|l|}
\hline Özellik & Markör & Kromozom & $\mathrm{F}$ & $\mathrm{p}$ \\
\hline Gövde & BNL3103 & 10 & 8.4852 & 0.0046 \\
\hline Koza & BNL2646 & - & 9.9442 & 0.0022 \\
\hline Koza & BNL3449 & 7 & 8.6702 & 0.0042 \\
\hline Koza & BNL387 & 7 & 14.9775 & 0.0002 \\
\hline Koza & BNL3492 & 9 & 9.7826 & 0.0025 \\
\hline Koza & BNL3535 & 19 & 10.1035 & 0.0021 \\
\hline Koza & BNL3627 & 8,24 & 7.4730 & 0.0076 \\
\hline Koza & BNL3895 & 11 & 13.2031 & 0.0005 \\
\hline Koza & NAU2714 & - & 9.9442 & 0.0022 \\
\hline Koza & NAU2761 & - & 8.2822 & 0.0051 \\
\hline Koza & NAU1302 & - & 8.2822 & 0.0051 \\
\hline Koza & JESPR178 & 18 & 16.4533 & 0.0001 \\
\hline Koza & JESPR230 & $9,19,22$ & 7.7406 & 0.0066 \\
\hline Yaprak & BNL3103 & 10 & 8.7439 & 0.0040 \\
\hline Yaprak & JESPR7 & 16,20 & 9.6225 & 0.0026 \\
\hline Yaprak & MUCS404 & - & 7.3521 & 0.0081 \\
\hline Tohum & BNL3535 & 19 & 7.2189 & 0.0087 \\
\hline Tohum & JESPR178 & 18 & 7.0981 & 0.0092 \\
\hline Tohum & JESPR230 & $9,19,22$ & 6.9442 & 0.0100 \\
\hline
\end{tabular}

Her iki yöntemde de BNL3130 (Kromozom 10), BNL3627 (Kromozom 8 ve 24), JESPR7 (Kromozom 16 ve 20), BNL3449 (Kromozom 7), BNL387 (Kromozom 4 ve 9) JESPER178 (Kromozom 18) markörleri belirlenmiştir. Pamukta gossypol oluşumunun $g l l, g l 2, g l 3, g l 4, g l 5$ ve $g l 6$ genleri tarafindan kontrol edildiği (Pauly, 1979), birbirlerinin homoloğu olan $G l 2$ ve $G l 3$ dominant genleri tarafindan kontrol edildiği bildirilmektedir (Vroh Bi ve ark., 1999). Liu ve ark (2012) tarafindan yapılan çalışmada pamuk $2,3,5,10,18$ ve 22 . Kromozomlarında gossypol ile ilişkili markörler belirlenmiștir. Yu ve ark. (2012) tarafindan yapılan çalışmada 13. ve 19. kromozomlarda gossypolle ilişkili markör belirlenmiștir. Bu çalışmada da benzer kromozomlarda markör belirlendiği görülmektedir.

\section{SONUC}

Genel linear modelde (GLM); gövdedeki gossypol ile ilişkili 1 adet, kozadaki gossypol ile ilişsi 4 adet, yapraktaki gossypol ile ilişkili 3 adet, tohumdaki gossypol ile ilișkili 8 adet, tohum HPLC sonuçları ile ilişkili 4 adet markör belirlenmiștir. Karıșık linear modelde (MLM) ise gövdedeki gossypol ile ilişkili 1 adet, kozadaki gossypol ile ilişki 12 adet, yapraktaki gossypol ile ilişkili 3 adet, tohumdaki gossypol ile ilişkili 3 adet markör belirlenmiștir. Her iki yöntemde de BNL3130, BNL3627, JESPR7, BNL3449, BNL387 ve JESPER178 markörleri belirlenmiştir.

$\mathrm{Bu}$ çalışmanın sonucunda ilişkilendirme haritalaması çalıșmalarının daha geniş popülasyonlar kullanılarak yapılması gerektiği, markör sayısının ve çeşitliliğinin arttrilarak genomu daha fazla temsil edecek şekilde yapılması gerektiği düşünülmektedir. Öte yandan kullanılan markör ve genotip sayısının az olmasına karşın kullanılabilecek markörlerin belirlendiğinin göz ardı edilmemesi gerektiği ve belirlenen markörlerin aynı ana ve babadan gelen özel popülasyonlarda $\left(\mathrm{F}_{2}, \mathrm{BC}_{1}\right.$, $\mathrm{BC}$, RIL) doğrulamasının yapılarak, uyumlu sonuç veren markörlerin markör destekli seleksiyonda kullanılabileceği sonucuna varılmıştır.

\section{KAYNAKLAR}

Abdurakhmonov IY, Kohel RJ, Yu JZ, Pepper AE, Abdullaev AA, Kushanov FN, Jenkins JN 2008. Molecular diversity and association mapping of fiber quality traits in exotic G. hirsutum L. germplasm. Genomics, 92(6), 478-487.

Altman DW, Stelly DM, Kohel RJ 1987. Introgression of Glanded-Plant and Glandless-Seed Trait from Gossypium sturtianum Willis into Cultivated Upland Cotton Using Ovule Culture. Crop Science., 27: 880-884.

Anonim 2017. Oilseeds: World Markets and Trade 2017 http://usda.mannlib.cornell.edu/usda/fas/oilseedtrade//2010s/2017/oilseed-trade-08-10-2017.pdf (Erişim Tarihi:09.10.2017).

Bardak A, Bölek Y 2012. Genetic diversity of diploid and tetraploid cottons determined by SSR and ISSR markers. Turkish Journal of Field Crop 17(2), 139144.

Bardak A 2017. Pamukta İlișkilendirme Haritalaması Yöntemiyle Markör Geliştirme. Bursa Tarım Kongresi, 13-15 Ekim 2016, sayfa1-10, Bursa. 
Benbouza H, Lacape JM, Jacquemin JM, Courtois B, Diouf FBH, Sarr D, Mergeai G 2010. Introgression of the low-gossypol seed \& high-gossypol plant trait in upland cotton: Analysis of [(Gossypium hirsutum $\times$ G. raimondii) ${ }^{2 \times}$ G. sturtianum] trispecific hybrid and selected derivatives using mapped SSRs. Molecular breeding, 25(2), 273-286.

Bolek Y, Tekerek H, Hayat K, Bardak A 2016. Screening of cotton genotypes for protein content, oil and fatty acid composition. Journal of Agricultural Science, 8(5), 107.

Buser MD, Abbas HK 2001. Update on the Impact of Dry Extruding Cottonseed to Reduce Aflatoxin and Gosspyol Levels. Proceedings of the Beltwide Cotton Conference, 2: 1392-1403.

Cherry JP, Simmons JG, Kohel RJ 1978. Cottonseed Composition of National Variety Test Cultivars Grown at Different Texas Locations. In: Proceedings of the Beltwide Cotton Production Research Conference, Brown, J.M. (Ed.). National Cotton Council of America, Memphis, Tenn., USA., pp: 4750.

Cherry JP 1983. Cottonseed oil. J. Am. Oil Chem. Soc., 60: 360-367.

Cherry JP, Leffler HR 1984. Seed. In: Cotton, Kohel, R.J. and C.F. Lewis (Eds.). ASA Publishers, Madison, Wisconsin, pp: 511-569.

Endrizzi JE 1962. The Diploid Like Cytological Behavior of Tetraploid Cotton. Evolution, 16: 325329.

Emiroğlu SH 1974. Gossypol Glandı Tasımayan Pamuk Islahı ve Glandsız Bazı İntrodüksiyon Pamuklarının Ticari Çesitlerle Karsılastırmalı Verim ve Kaliteleri Üzerinde Arastırmalar. Ege Üniversitesi Ziraat Fakültesi, Doçentlik Tezi, İzmir, 1-20.

Kohel RJ 1973. Genetic Nomenclature in Cotton. Journal of Heredity, 65: 291-295.

Liu G, Mei H, Wang S, Li X, Zhu X, Zhang T 2015. Association mapping of seed oil and protein contents in upland cotton. Euphytica, 205(2), 637-645.

Lusas EW, Lividin GM 1987. Glandless Cottonseed: A Review of the First 25 Years of Processing and Utilization Research. Journal of American Oil Chemists' Society, 64: 839-854.
McMichael SC 1954. Glandiess boll in upland cotton and its use in the study of natural crossing. Agron. J. 46:527.

Pauly G 1979. Les Glandles à Pigments du Cotonnier: Aspect Génétique et Sélection dés Variétés 'Glandless' et 'High Gossypol'. Cotton Fibres Trop. 34: 379-402.

Percy RG, Calhoun MC, Kim HL 1996. Seed gossypol variation within Gossypium barbadense L. cotton. Crop science, 36(1), 193-197.

Pritchard JK, Stephens M, Donnelly P 2000 Inference of population structure using multilocus genotype data. Genetics 155:945-959.

Rooney WL, Stelly DM, Altman DW 1991. Identification of Four Gossypium sturtianum Monosomic Alien Addition Derivatives from a Backcrossing Program with G.hirsutum L. Crop Science. 31: 337-341.

Samora PJ, Stelly DM, Kohel RJ 1994. Localization and Mapping of GL1 and GL2 Loci of Cotton (G.hirsutum L.). Journal of Heredity, 85:152-157.

Sezer Ö 1981. Bölgede Ekilen Islah, Deneme ve Arastırma Projelerinde Denenen Pamuk Çesitlerinin Koza, Tohum, Lif ve İplik Özelliklerinin Tayini. Adana Bölge Pamuk Arastırma Enstitüsü, Pamuk Arastırma Proje ve Sonuçları, 183-189.

Stipanovic RD 1994. Gossypol in Cotton. Proceedings, The Biochemistry of Cotton Workshop, 23-27.

Vroh Bi I, Baudoin JP, Hau B, Mergeai G 1999. Development of High Gossypol Cotton Plants with Low Gossypol Seeds Using Trispecies Bridge Crosses and In Vitro Culture of Seed Embryos. Euphytica, 106: 243-251.

Yu J, Yu S, Fan S, Song M, Zhai H, Li X, Zhang J 2012. Mapping quantitative trait loci for cottonseed oil, protein and gossypol content in a Gossypium hirsutum $\times$ Gossypium barbadense backcross inbred line population. Euphytica, 187(2), 191-201.

Zhang J, Stewar, McD 2000. Economical and Rapid Method for Extracting Cotton Genomic DNA. The Journal of Cotton Science, 4,193-201.

Zhu C, Gore M, Buckler ES, Yu J 2008. Status and prospects of association mapping in plants. Plant Genome $\quad 1, \quad 5-20 . \quad$ doi: 10.3835/plantgenome2008.02.0089. 